\title{
The structure of edible potato crops (Solanum tuberosum L.) under conditions of the application of microbiological product UGmax
}

\section{Struktura plonu ziemniaka jadalnego (Solanum tuberosum L.) w warunkach stosowania preparatu mikrobiologicznego UGmax}

\author{
Krystyna Zarzecka ${ }^{1}$, Alicja Baranowska ${ }^{2 *}$, Iwona Mystkowska², Marek Gugała ${ }^{1}$
}

\begin{abstract}
Summary
The objective of the research was to evaluate the effect of microbiological product UGmax on the structure of potato yield. The experiment was designed as a two-factor randomized block with three replications. The study included two factors: two medium early varieties of edible potato - Satina and Tajfun, and five treatments of using UGmax soil fertilizer at different doses and various dates. The obtained result showed that the UGmax soil fertilizer had a beneficial effect on the potato yield structure. The highest percentage of tubers with the fractions from 35 to $60 \mathrm{~mm}$ was recorded for the UGmax applied before tubers planting at a dose of $1.0 \mathrm{dm}^{3} / \mathrm{ha}$ and when the height of plants was about 10-15 cm, and at the flower buds making phase at a dose of $0.5 \mathrm{dm}^{3} / \mathrm{ha}$, and application of examined product to soil before planting tubers at a dose of $0.5 \mathrm{dm}^{3} / \mathrm{ha}$, when the height of plants was about 10-15 cm, and also at the flower buds making phase at a dose of $0.25 \mathrm{dm}^{3} /$ ha. The data proved that individual potato tuber fractions were modified by two factors such as variety type and weather conditions.
\end{abstract}

Key words: potato; yield structure; microbiological product

\begin{abstract}
Streszczenie
Celem eksperymentu było określenie wpływu preparatu mikrobiologicznego UGmax na strukturę plonu ziemniaka. Doświadczenie założono metodą losowanych podbloków w trzech powtórzeniach. Badanymi czynnikami były: I. dwie średnio wczesne odmiany ziemniaka jadalnego - Satina i Tajfun, II. pięć sposobów stosowania Użyźniacza Glebowego UGmax w różnych dawkach i terminach. W wyniku przeprowadzonych badań wykazano, że Użyźniacz Glebowy UGmax korzystnie wpływał na strukturę plonu ziemniaka. Największy udział procentowy bulw we frakcjach od 35 do $60 \mathrm{~mm}$ odnotowano po zastosowaniu preparatu UGmax przed sadzeniem bulw w dawce $1,0 \mathrm{dm}^{3} /$ ha i przy wysokości roślin $10-15 \mathrm{~cm}$ i w fazie pąków kwiatowych po $0,5 \mathrm{dm}^{3} /$ ha oraz po aplikacji UGmax przed sadzeniem bulw w dawce $0,5 \mathrm{dm}^{3} /$ ha przy wysokości roślin $10-15 \mathrm{~cm}$ i w fazie pąków kwiatowych po 0,25 dm³/ha. Wykazano, że poszczególne frakcje bulw ziemniaka były modyfikowane przez czynnik odmianowy i warunki pogodowe.
\end{abstract}

Słowa kluczowe: ziemniak; struktura plonu; preparat mikrobiologiczny

\footnotetext{
Uniwersytet Przyrodniczo-Humanistyczny w Siedlcach

Katedra Agrotechnologii, Prusa 14, 08-110 Siedlce

${ }^{2}$ Państwowa Szkoła Wyższa im. Papieża Jana Pawła II w Białej Podlaskiej

Zakład Rolnictwa, Sidorska 95/97, 21-500 Biała Podlaska

*corresponding author: alabar@tlen.pl
} 


\section{Wstęp / Introduction}

Zgodnie z danymi Food and Agriculture Organization of the United Nations ziemniak jest jedną z głównych roślin uprawianych na świecie. Obecnie światowa produkcja tej rośliny szacowana jest na ponad $385,1 \mathrm{mln}$ ton (FAO 2017).

W rolnictwie 21. wieku idea ochrony środowiska naturalnego, bioróżnorodności i konsumenta staje się coraz bardziej popularna i prowadzi do poszukiwania proekologicznych metod uprawy roślin, których głównym zadaniem jest między innymi zwiększenie żyzności gleby poprzez poprawę parametrów fizycznych, chemicznych i biologicznych. Działania te mają na celu produkcję bezpiecznej żywności w poszanowaniu środowiska przyrodniczego (Mrówczyński i Roth 2009; Kocoń i Gałązka 2015). Tendencje te widoczne są również $\mathrm{w}$ agrotechnice ziemniaka. Coraz większe wymagania konsumentów w odniesieniu do jakości bulw skłaniają producentów do doskonalenia technologii uprawy tej rośliny (Zarzecka i wsp. 2017).

$\mathrm{W}$ produkcji roślinnej, w tym również na plantacjach ziemniaka stosowane są różnego rodzaju preparaty mikrobiologiczne zawierające pożyteczne mikroorganizmy, które wzbogacają życie biologiczne gleby. Stwarzają one siedlisko sprzyjające rozwojowi roślin, biorą udział $\mathrm{w}$ procesach związanych $\mathrm{z}$ odżywaniem roślin poprzez przyspieszenie procesu rozkładu szczątków organicznych w glebie oraz zwiększanie dostępności mikro- i makroelementów i w ten sposób oddziałują również na właściwości plonotwórcze. Stosowanie preparatów biologicznych może przyczynić się do produkcji żywności o wysokiej jakości w systemie przyjaznym dla agrocenozy (Barea i wsp. 2005; Trawczyński i Bogdanowicz 2007; Zarzecka i Gugała 2013; Kosicka i wsp. 2015; Kowalska 2016).

Nieliczne dotychczas wyniki empiryczne na temat wpływu preparatów mikrobiologicznych na strukturę plonu ziemniaka jadalnego, jak również na środowisko glebowe skłaniają do prowadzenia dalszych badań.

Celem eksperymentu było określenie wpływu Użyźniacza Glebowego UGmax stosowanego w różnych terminach i dawkach na strukturę wagową plonu dwóch odmian ziemniaka jadalnego.

\section{Materiały i metody / Materials and methods}

Trzyletni eksperyment polowy prowadzono w Rolniczej Stacji Doświadczalnej Zawady w rejonie centralnej Polski $\left(52^{\circ} 03^{\prime} \mathrm{N}, 22^{\circ} 33^{\prime} \mathrm{E}\right)$. Doświadczenie przeprowadzono na glebie o składzie granulometrycznym gliny piaszczystej, o odczynie lekko kwaśnym i kwaśnym $(4,81-5,91$ pH w $1 \mathrm{n} \mathrm{KCl)}$. Zasobność gleby w przyswajalny fosfor była od wysokiej do bardzo wysokiej, potas od niskiej do wysokiej i magnez od niskiej do średniej. Eksperyment założono metodą losowanych podbloków (split-plot) w trzech powtórzeniach. Materiał badawczy stanowiły bulwy ziemniaka jadalnego.

Badanymi czynnikami były: I. dwie średnio wczesne odmiany ziemniaka jadalnego - Satina i Tajfun, II. pięć sposobów stosowania Użyźniacza Glebowego UGmax w różnych dawkach i terminach: 1. obiekt kontrolny bez UGmax, 2. UGmax doglebowo przed sadzeniem bulw w dawce $1,0 \mathrm{dm}^{3} / \mathrm{ha}, 3$. UGmax doglebowo przed sadzeniem bulw w dawce $0,5 \mathrm{dm}^{3} / \mathrm{ha}$, przy wysokości roślin $10-15 \mathrm{~cm}$ i w fazie pąków kwiatowych w dawce $0,25 \mathrm{dm}^{3} / \mathrm{ha}, 4$. UGmax przed sadzeniem bulw w dawce $1,0 \mathrm{dm}^{3} /$ ha i przy wysokości roślin 10-15 $\mathrm{cm}$ oraz $\mathrm{w}$ fazie pąków kwiatowych po $0,5 \mathrm{dm}^{3} /$ ha, 5. UGmax przy wysokości roślin $10-15 \mathrm{~cm}$ i w fazie pąków kwiatowych w dawce $0,5 \mathrm{dm}^{3} /$ ha. Użyźniacz glebowy rozpuszczono w $300 \mathrm{dm}^{3}$ wody w przeliczeniu na 1 ha. Zgodnie z zaleceniem producenta (P.P.H.U. BOGDAN) preparat mikrobiologiczny UGmax aplikowano w godzinach popołudniowych $\mathrm{w}$ formie opryskiwania średnio kroplistego na wilgotną, ciepłą glebę, $w$ temperaturze powietrza wynoszącej $12^{\circ} \mathrm{C}$.

Preparat mikrobiologiczny UGmax jest ekstraktem z obornika i gnojowicy zawierającym szczepionkę mikroorganizmów glebowych. W jego skład wchodzą: promieniowce, drożdże, bakterie kwasu mlekowego, bakterie Pseudomonas, Azotobacter oraz makro- i mikroelementy: potas $(3500 \mathrm{mg} / \mathrm{l})$, azot $(1200 \mathrm{mg} / \mathrm{l})$, siarka $(1000 \mathrm{mg} / \mathrm{l})$, fosfor $(500 \mathrm{mg} / \mathrm{l})$, sód $(200 \mathrm{mg} / \mathrm{l})$, magnez $(100 \mathrm{mg} / \mathrm{l})$, cynk $(20 \mathrm{mg} / \mathrm{l})$ i mangan $(0,3 \mathrm{mg} / \mathrm{l})$ (Trawczyński i Bogdanowicz 2007; Kocoń i Gałązka 2015).

Ziemniaka uprawiano w płodozmianie po zbożach ozimych. Jesienią, przed założeniem doświadczenia stosowano obornik $\mathrm{w}$ dawce $25 \mathrm{t} / \mathrm{ha}$ oraz nawożenie fosforowe: $\mathrm{P}-44,0 \mathrm{~kg} / \mathrm{ha}$ (superfosfat potrójny $46 \%$ ) i potasowe $\mathrm{K}-124,5 \mathrm{~kg} / \mathrm{ha}$ (sól potasowa $60 \%$ ), a wiosną nawożenie azotowe (saletra amonowa 34\%) w dawce $100 \mathrm{~kg} \mathrm{~N} / \mathrm{ha}$. Bulwy ziemniaka sadzono ręcznie $\mathrm{w}$ drugiej dekadzie kwietnia w rozstawie rzędów $67,5 \mathrm{~cm}$, co $37 \mathrm{~cm}$ w rzędzie. Powierzchnia jednego poletka wynosiła $15 \mathrm{~m}^{2}$. Przeciwko chwastom stosowano opryskiwanie mieszaniną herbicydów Command $480 \mathrm{SC} 0,2 \mathrm{dm}^{3} / \mathrm{ha}+$ Afalon Dyspersyjny $450 \mathrm{SC} 1,0 \mathrm{dm}^{3} / \mathrm{ha}$. Plantację chroniono przed zarazą ziemniaka (Phytophthora infestans) fungicydami: Ridomil Gold MZ 68 WG i Dithane 455 SC, a stonkę ziemniaczaną (Leptinotarsa decemlineata) zwalczano stosując insektycydy: Apacz 50 WG i Actara 25 WG. Środki ochrony roślin stosowano zgodnie z zaleceniami zawartymi w etykietach. Każdego roku przed zbiorem pobrano próby bulw z dziesięciu losowo wybranych roślin ziemniaka (z wyłączeniem roślin brzeżnych), w których określono strukturę plonu według frakcji o średnicy poprzecznej: $<35,36-50,51-60,>60,>35 \mathrm{do}>60,>50$ (Rozporządzenie 
2003). Plon ogólny ziemniaka wyliczono na podstawie masy bulw zebranych z powierzchni poletka dodając masę wcześniej pobranych prób, a wyniki z plonowania i struktury liczbowej plonu przedstawiono we wcześniejszej pracy Zarzeckiej i Gugały (2013). Zbioru dokonywano w okresie dojrzałości technologicznej bulw, w pierwszej dekadzie września. Wyniki badań dotyczące wpływu preparatu UGmax na strukturę plonu ziemniaka jadalnego oparto na średnich wartościach procentowych.

Warunki pogodowe w okresie wegetacji ziemniaka oceniono na podstawie średniej temperatury powietrza i sumy opadów w porównaniu do wartości średnich z okresu wieloletniego (tab. 1). Najkorzystniejszym sezonem do wzrostu i rozwoju roślin ziemniaka był rok 2008, który charakteryzował się temperaturą zbliżoną do panującej w okresie wieloletnim i dobrze rozłożonymi opadami. W 2009 roku średnia temperatura powietrza była wyższa od średniej wieloletniej, a opady przekraczały średnią sumę wieloletnią i były nierównomiernie rozłożone. Natomiast rok 2010 był najcieplejszy i najbardziej wilgotny (tab. 1).

\section{Wyniki i dyskusja / Results and discussion}

Wyrazem dbałości o jakość i wielkość zebranych plonów oraz troski o środowisko przyrodnicze jest wprowadzanie do agrotechniki ziemniaka różnego rodzaju preparatów mikrobiologicznych. Wzbogacają one glebę w próchnicę, poprawiają zdrowotność i odporność roślin na warunki stresowe, ułatwiają pobieranie składników pokarmowych, wpływają na wielkość i jakość zebranych plonów (Janas 2009; Nowacki 2010; Gajewski i wsp. 2013; Baranowska i wsp. 2017).

Analizując wyniki badań własnych stwierdzono, że preparat mikrobiologiczny UGmax oddziaływał korzystnie na strukturę plonu bulw ziemniaka. Największy udział procentowy bulw we frakcjach od $35 \mathrm{~mm}$ do $60 \mathrm{~mm}$ odnotowano na obiekcie 4., na którym UGmax stosowano na wilgotną glebę przed sadzeniem i dwukrotnie podczas wegetacji roślin (w ogólnej dawce 1,5 dm³/ha) oraz na obiekcie 3., na którym Użyźniacz Glebowy UGmax aplikowano doglebowo przed sadzeniem bulw w dawce $0,5 \mathrm{dm}^{3} /$ ha, przy wysokości roślin 10-15 cm i w fazie pąków kwiatowych po $0,25 \mathrm{dm}^{3} /$ ha (w ogólnej dawce $0,75 \mathrm{dm}^{3} / \mathrm{ha}$ ). Natomiast największy procent bulw drobnych, o średnicy poniżej $35 \mathrm{~mm}$ zebrano z obiektu kontrolnego, na którym nie aplikowano preparatu mikrobiologicznego (tab. 1). Korzystny wpływ preparatu UGmax na plon ziemniaka i jego strukturę stwierdzili również Bernat (2007), Trawczyński i Bogdanowicz (2007), Szewczuk i wsp. (2016). Kowalska (2016) odnotowała korzystne oddziaływanie preparatów mikrobiologicznych na plon ziemniaka i jego strukturę bez względu na stosowany preparat i formę jego aplikacji. Kocoń i Jadczyszyn (2015) w trzyletnich badaniach wykazały, że preparat UGmax wpływał na poprawę parametrów żyzności gleby i wielkość zebranych plonów. Natomiast Martyniuk i Księżak (2011) w jednorocznych badaniach polowych prowadzonych na glebie zaliczonej do kompleksu żytniego bardzo dobrego nie odnotowali korzystnego wpływu preparatów biologicznych na wybrane elementy struktury plonu. Maciejewski i Rębarz (2011) udowodnili, że aplikacja UGmax nie miała wpływu na elementy plonotwórcze ziemniaka. Condor i wsp. (2006) wyrazili sceptyczny pogląd na temat stosowania preparatów mikrobiologicznych w uprawach rolniczych, podkreślając potrzebę prowadzenia dalszych badań naukowych dotyczących ich stosowania.

W badaniach własnych poszczególne frakcje bulw były modyfikowane przez czynnik odmianowy. Analizując wpływ odmian na procentowy wagowy udział frakcji stwierdzono, że odmiana Tajfun charakteryzowała się większym udziałem

Tabela 1. Temperatura powietrza i opady w czasie wegetacji ziemniaka w latach 2008-2010 według Stacji Meteorologicznej w Zawadach

Table 1. Air temperature and rainfall in the vegetation period of potato in 2008-2010 at the Zawady Meteorological Station

\begin{tabular}{|c|c|c|c|c|c|c|c|c|}
\hline \multirow{4}{*}{$\begin{array}{l}\text { Miesiące } \\
\text { Months }\end{array}$} & \multicolumn{4}{|c|}{ Temperatura powietrza - Air temperature $\left[{ }^{\circ} \mathrm{C}\right]$} & \multicolumn{4}{|c|}{ Opady - Rainfall [mm] } \\
\hline & \multirow{3}{*}{$\begin{array}{c}\text { średnia wieloletnia } \\
\text { 23-year mean } \\
1987-2010\end{array}$} & \multirow{2}{*}{\multicolumn{3}{|c|}{$\begin{array}{l}\text { średnia } \\
\text { mean }\end{array}$}} & \multirow{3}{*}{$\begin{array}{c}\text { średnia wieloletnia } \\
\text { 23-year mean } \\
1987-2010\end{array}$} & \multirow{2}{*}{\multicolumn{3}{|c|}{$\begin{array}{l}\text { suma } \\
\text { sum }\end{array}$}} \\
\hline & & & & & & & & \\
\hline & & 2008 & 2009 & 2010 & & 2008 & 2009 & 2010 \\
\hline IV & 7,8 & 9,1 & 10,3 & 8,9 & 38,6 & 28,2 & 8,1 & 10,7 \\
\hline $\mathrm{V}$ & 12,5 & 12,7 & 12,9 & 14,0 & 44,1 & 85,6 & 68,9 & 93,2 \\
\hline VI & 17,2 & 17,4 & 15,7 & 17,4 & 52,4 & 49,0 & 145,2 & 62,6 \\
\hline VII & 19,2 & 18,4 & 19,4 & 21,6 & 49,8 & 69,8 & 26,4 & 77,0 \\
\hline VIII & 18,5 & 18,5 & 17,7 & 19,8 & 43,0 & 75,4 & 80,9 & 106,3 \\
\hline IX & 13,1 & 12,2 & 14,6 & 11,8 & 47,3 & 63,4 & 24,9 & 109,9 \\
\hline IV-IX & $\begin{array}{c}\text { średnio - mean } \\
14,7\end{array}$ & 14,7 & 15,1 & 15,6 & $\begin{array}{c}\text { suma - sum } \\
275,2\end{array}$ & 371,4 & 354,4 & 459,7 \\
\hline
\end{tabular}


Tabela 2. Wpływ preparatu UGmax na procentowy wagowy udział frakcji bulw ziemniaka jadalnego (średnio dla odmian i lat 2008-2010) Table 2. Effect of UGmax formulation on the percentage and weight fraction of tubers of edible potato (average for varieties and years 2008-2010)

\begin{tabular}{l|c|c|c|c|c|c}
\hline \multirow{2}{*}{ Obiekty - Treatments } & \multicolumn{5}{c}{ Frakcje - Fraction [mm] } \\
\cline { 2 - 8 } & $<35$ & $36-50$ & $51-60$ & $>60$ & $>35$ do $>60$ & $>50$ \\
\hline 1. Obiekt kontrolny - Control & 7,2 & 22,5 & 39,2 & 31,2 & 92,9 & 70,4 \\
\hline 2. UGmax 1,0 $+0 \mathrm{dm}^{3} / \mathrm{ha}$ & 4,2 & 22,8 & 33,5 & 39,5 & 95,8 & 73,0 \\
\hline 3. UGmax 0,5+0,25+0,25 dm $3 / \mathrm{ha}$ & 3,6 & 19,2 & 38,9 & 38,4 & 96,5 & 77,3 \\
\hline 4. UGmax 1,0 $+0,25+0,25 \mathrm{dm}^{3} / \mathrm{ha}$ & 3,2 & 18,7 & 38,2 & 40,0 & 96,9 & 78,2 \\
\hline 5. UGmax 0 + 0,5 +0,5 dm $3 / \mathrm{ha}$ & 5,4 & 25,0 & 35,9 & 33,9 & 94,8 & 69,8 \\
\hline Średnio - Mean & 4,7 & 21,6 & 37,1 & 36,6 & 95,3 & 73,7 \\
\hline
\end{tabular}

Tabela 3. Wpływ preparatu UGmax na procentowy wagowy udział frakcji bulw ziemniaka jadalnego odmiany Tajfun (średnio dla lat 2008-2010)

Table 3. Effect of UGmax formulation on the percentage and weight fraction of tubers of edible potato Tajfun variety (average for years 2008-2010)

\begin{tabular}{|c|c|c|c|c|c|c|}
\hline \multirow{2}{*}{ Obiekty - Treatments } & \multicolumn{6}{|c|}{ Frakcje - Fraction $[\mathrm{mm}]$} \\
\hline & $<35$ & $36-50$ & $51-60$ & $>60$ & $>35$ do $>60$ & $>50$ \\
\hline 1. Obiekt kontrolny - Control & 6,2 & 21,6 & 40,0 & 32,2 & 93,8 & 72,2 \\
\hline 2. UGmax $1,0+0 \mathrm{dm}^{3} / \mathrm{ha}$ & 3,4 & 21,9 & 32,8 & 41,9 & 96,6 & 41,9 \\
\hline 3. UGmax $0,5+0,25+0,25 \mathrm{dm}^{3} / \mathrm{ha}$ & 2,7 & 19,7 & 39,7 & 37,9 & 97,3 & 77,6 \\
\hline 4. UGmax $1,0+0,25+0,25 \mathrm{dm}^{3} / \mathrm{ha}$ & 2,4 & 20,4 & 37,5 & 39,6 & 97,5 & 77,1 \\
\hline 5. UGmax $0+0,5+0,5 \mathrm{dm}^{3} / \mathrm{ha}$ & 5,1 & 22,0 & 37,4 & 35,5 & 94,9 & 72,9 \\
\hline Średnio - Mean & 4,0 & 21,1 & 37,5 & 37,4 & 96,0 & 74,9 \\
\hline
\end{tabular}

Tabela 4. Wpływ preparatu UGmax na procentowy wagowy udział frakcji bulw ziemniaka jadalnego odmiany Satina (średnio dla lat 2008-2010)

Table 4. Effect of UGmax formulation on the percentage and weight fraction of tubers of edible potato Satina variety (average for years 2008-2010)

\begin{tabular}{|c|c|c|c|c|c|c|}
\hline \multirow{2}{*}{ Obiekty - Treatments } & \multicolumn{6}{|c|}{ Frakcje - Fraction [mm] } \\
\hline & $<35$ & $36-50$ & $51-60$ & $>60$ & $>35$ do $>60$ & $>50$ \\
\hline 1. Obiekt kontrolny - Control & 8,2 & 23,4 & 38,1 & 30,1 & 91,8 & 68,4 \\
\hline 2. UGmax $1,0+0 \mathrm{dm}^{3} / \mathrm{ha}$ & 5,0 & 23,6 & 34,2 & 37,1 & 94,9 & 71,3 \\
\hline 3. UGmax $0,5+0,25+0,25 \mathrm{dm}^{3} / \mathrm{ha}$ & 4,5 & 18,7 & 38,0 & 38,8 & 95,5 & 76,8 \\
\hline 4. UGmax $1,0+0,25+0,25 \mathrm{dm}^{3} / \mathrm{ha}$ & 3,9 & 17,0 & 38,8 & 40,3 & 96,1 & 79,1 \\
\hline 5. UGmax $0+0,5+0,5 \mathrm{dm}^{3} / \mathrm{ha}$ & 5,6 & 27,9 & 34,3 & 32,2 & 94,4 & 66,5 \\
\hline Średnio - Mean & 5,4 & 22,1 & 36,8 & 35,7 & 94,6 & 72,5 \\
\hline
\end{tabular}

bulw o średnicy od 35 do $60 \mathrm{~mm}$ niż odmiana Satina (tab. 2-4). Sawicka i Pszczółkowski (2004) oraz Turska i wsp. (2009) udowodnili, że strukturę plonu ziemniaka modyfikują cechy genetyczne odmian. Autorzy podkreślili również, że o wykorzystaniu możliwości plonotwórczych danej odmiany decyduje właściwa agrotechnika.

Strukturę plonu ziemniaka kształtowały warunki pogodowe w latach badań. Najbardziej korzystnym dla kształtowania plonu i jego struktury był sezon wegetacyjny 2008 roku, który charakteryzował się temperaturą powietrza zbliżoną do panującej w okresie wieloletnim. Opady były większe o 96,2 mm niż w okresie wieloletnim, ale były dobrze rozłożone $\mathrm{w}$ poszczególnych miesiącach wegetacji (tab. 1).

Udział masy bulw o średnicy 35-60 mm w plonie wyniósł średnio 96,2\% (tab. 5). Zdaniem Kocoń i Gałązki (2015) stosowanie preparatów mikrobiologicznych w korzystnych sezonach wegetacyjnych wpływa pozytywnie na plonowanie roślin. Schenck i Müller (2009), a także Kocoń i Jadczyszyn (2015) wykazali, że większa i dobrze rozłożona w czasie ilość opadów oraz wyższe temperatury powietrza $\mathrm{w}$ stosunku do średnich $\mathrm{z}$ wielolecia sprzyjały rozwojowi 
Tabela 5. Wpływ preparatu UGmax na procentowy wagowy udział frakcji bulw ziemniaka jadalnego w latach badań (średnio dla odmian)

Table 5. Effect of UGmax formulation on the percentage and weight fraction of tubers of edible potato in years of research (average for varieties)

\begin{tabular}{|c|c|c|c|c|c|c|}
\hline \multirow{2}{*}{ Obiekty - Treatments } & \multicolumn{6}{|c|}{ Frakcje - Fraction $[\mathrm{mm}]$} \\
\hline & $<35$ & $36-50$ & $51-60$ & $>60$ & $>35$ do $>60$ & $>50$ \\
\hline \multicolumn{7}{|c|}{2008} \\
\hline 1. Obiekt kontrolny - Control & 5,0 & 21,3 & 2,5 & 44,3 & 95,0 & 73,8 \\
\hline 2. UGmax $1,0+0 \mathrm{dm}^{3} / \mathrm{ha}$ & 3,5 & 16,3 & 26,6 & 53,6 & 96,5 & 80,2 \\
\hline 3. UGmax $0,5+0,25+0,25 \mathrm{dm}^{3} / \mathrm{ha}$ & 3,1 & 15,1 & 34,9 & 46,9 & 96,9 & 81,8 \\
\hline 4. UGmax $1,0+0,25+0,25 \mathrm{dm}^{3} / \mathrm{ha}$ & 3,1 & 13,3 & 29,3 & 54,3 & 97,0 & 83,6 \\
\hline 5. UGmax $0+0,5+0,5 \mathrm{dm}^{3} / \mathrm{ha}$ & 4,1 & 19,5 & 25,3 & 51,2 & 96,0 & 76,5 \\
\hline Średnio - Mean & 3,8 & 17,1 & 29,1 & 50,0 & 96,2 & 79,1 \\
\hline \multicolumn{7}{|c|}{2009} \\
\hline 1. Obiekt kontrolny - Control & 7,9 & 28,2 & 49,8 & 14,1 & 92,1 & 63,9 \\
\hline 2. UGmax $1,0+0 \mathrm{dm}^{3} / \mathrm{ha}$ & 5,3 & 26,1 & 44,5 & 24,2 & 94,7 & 68,7 \\
\hline 3. UGmax $0,5+0,25+0,25 \mathrm{dm}^{3} / \mathrm{ha}$ & 4,9 & 23,2 & 39,9 & 32,1 & 95,1 & 72,0 \\
\hline 4. UGmax $1,0+0,25+0,25 \mathrm{dm}^{3} / \mathrm{ha}$ & 4,3 & 24,2 & 39,2 & 32,4 & 95,7 & 72,5 \\
\hline 5. UGmax $0+0,5+0,5 \mathrm{dm}^{3} / \mathrm{ha}$ & 7,0 & 28,5 & 42,7 & 21,8 & 93,0 & 64,5 \\
\hline Średnio - Mean & 5,9 & 26,0 & 43,2 & 24,9 & 94,1 & 68,1 \\
\hline \multicolumn{7}{|c|}{2010} \\
\hline 1. Obiekt kontrolny - Control & 8,8 & 18,0 & 38,2 & 35,1 & 91,3 & 73,3 \\
\hline 2. UGmax $1,0+0 \mathrm{dm}^{3} / \mathrm{ha}$ & 3,8 & 26,1 & 29,4 & 40,8 & 96,2 & 70,2 \\
\hline 3. UGmax $0,5+0,25+0,25 \mathrm{dm}^{3} / \mathrm{ha}$ & 2,8 & 19,5 & 41,8 & 36,0 & 97,2 & 77,8 \\
\hline 4. UGmax $1,0+0,25+0,25 \mathrm{dm}^{3} / \mathrm{ha}$ & 2,2 & 18,6 & 46,1 & 33,2 & 97,8 & 79,3 \\
\hline 5. UGmax $0+0,5+0,5 \mathrm{dm}^{3} / \mathrm{ha}$ & 5,0 & 26,9 & 39,6 & 28,6 & 95,1 & 68,2 \\
\hline Średnio - Mean & 4,5 & 21,8 & 39,0 & 34,7 & 95,5 & 73,7 \\
\hline
\end{tabular}

mikroorganizmów glebowych i zwiększały skuteczność działania preparatów mikrobiologicznych.

\section{Wnioski / Conclusions}

1. Użyźniacz Glebowy UGmax stosowany w różnych dawkach i terminach wpływał korzystnie na strukturę plonu bulw ziemniaka. Najbardziej efektywnymi były zabiegi z zastosowaniem preparatu UGmax przed sadzeniem bulw w dawce $1,0 \mathrm{dm}^{3} /$ ha $\mathrm{i}$ przy wysokości roślin $10-15 \mathrm{~cm}$ i w fazie pąów kwiatowych w dawce $0,5 \mathrm{dm}^{3} /$ ha oraz aplikacja preparatu UGmax przed sadzeniem bulw w dawce $0,5 \mathrm{dm}^{3} /$ ha, przy wysokości roślin 10-15 cm i w fazie pąków kwiatowych po $0,25 \mathrm{dm}^{3} /$ ha.
2. Uprawiane odmiany różniły się pod względem udziału poszczególnych frakcji w plonie. Odmiana Tajfun charakteryzowała się większym udziałem bulw o średnicy od 35 do $60 \mathrm{~mm}$ niż odmiana Satina.

3. Najbardziej korzystny wpływ preparatu UGmax na procentowy wagowy udział frakcji uzyskano w sezonie wegetacyjnym o równomiernie rozłożonych opadach i temperaturze powietrza zbliżonej do średniej wieloletniej.

\section{Podziękowanie / Acknowledgements}

Wyniki badań realizowane w ramach tematu badawczego numer 214/04/S zostały sfinansowane z dotacji na naukę, przyznanej przez Ministerstwo Nauki i Szkolnictwa Wyższego.

\section{Literatura / References}

Baranowska A.,Zarzecka K., Gugała M., Mystkowska I. 2017. Contents of zinc, copper and manganese in potato tubers depending on the ways of application of the soil fertilizer UGmax. Journal of Ecological Engineering 18 (1): 99-106. DOI: 10.12911/22998993/66250. 
Barea J.M., Pozo M.J., Azon R., Azon-Aguilar C. 2005. Microbial cooperation in the rhizosphere. Journal of Experimental Botany 56: 1761-1778. DOI: 10.1093/jxb/eri197.

Bernat E. 2007. Wpływ stosowania Użyźniacza Glebowego na plonowanie i zdrowotność ziemniaków. Materiały Konferencji NaukowoSzkoleniowej nt. Nasiennictwo i ochrona ziemniaka. Kołobrzeg, 19-20 kwietnia 2007: 43-46.

Condor A.F., Perez P.G., Lokare Ch. 2006. Effective microorganisms: myth or reality. Revista Peruana de Biologia 14 (2): 315-319.

FAO 2017. Food and Agriculture Organization of the United Nations 2017. Statistical Pocketbook World Food and Agriculture. http:// www.fao.org/3/a-i4691e.pdf. [Accessed: 27.10.2017].

Gajewski P., Kaczmarek A., Owczarzak W., Jakubas M., Mocek A. 2013. Wpływ dodatków organicznych oraz preparatu EM-A na właściwości fizyczne, chemiczne oraz na stan struktury poziomu orno-próchnicznego gleby uprawnej. Część III. Stan struktury. Journal of Research and Applications in Agricultural Engineering 58 (3): 119-123.

Janas R. 2009. Możliwości wykorzystania efektywnych mikroorganizmów w ekologicznych systemach produkcji roślin uprawnych. Problemy Inżynierii Rolniczej 3: 111-119.

Kocoń A., Gałązka A. 2015. Wpływ preparatów z mikroorganizmami pożytecznymi na właściwości fizykochemiczne gleby oraz plon roślin. Studia i Raporty Instytutu Uprawy Nawożenia i Gleboznawstwa 45 (19): 113-125.

Kocoń A., Jadczyszyn T. 2015. Wpływ preparatów mikrobiologicznych, sposobów ich stosowania oraz dawek nawożenia azotem na zawartość przyswajalnego fosforu w glebie i inne wybrane wskaźniki chemiczne żyzności gleby. Polish Journal of Agronomy 21: 11-18.

Kosicka D., Wolna-Murawka A., Trzeciak M. 2015. Wpływ preparatów mikrobiologicznych na glebę oraz wzrost i rozwój roślin. Kosmos Problemy Nauk Biologicznych 64 (2): 327-335.

Kowalska J. 2016. Wpływ nawożenia oraz biostymulatorów mikrobiologicznych na zdrowotność i plonowanie ziemniaka w systemie ekologicznym. [Effect of fertilization and microbiological bio-stimulators on healthiness and yield of organic potato]. Progress in Plant Protection/Postępy w Ochronie Roślin 56 (2): 230-235. DOI: 10.14199/ppp-2016-039.

Maciejewski T., Rębarz K. 2011. Wpływ stosowania UGmax na rozwój i plonowanie ziemniaków i pszenicy ozimej. Doniesienie. Materiały Konferencji Naukowo-Szkoleniowej nt. Nasiennictwo i ochrona ziemniaka. Darłówko, 19-20 maja 2011, 35 ss.

Martyniuk S., Księżak J. 2011. Ocena pseudomikrobiologicznych biopreparatów stosowanych w uprawie roślin. Polish Journal of Agronomy 6: 27-33.

Mrówczyński M., Roth M. 2009. Zrównoważone stosowanie środków ochrony roślin. Problemy Inżynierii Rolniczej 2: 93-97.

Nowacki W. 2010. Współczesne technologie i systemy uprawy ziemniaka. s. 7-11. W: Materiały Konferencji nt. Tradycja i nowoczesność w produkcji ziemniaka. Jadwisin, 7-9 lipca 2010, 134 ss.

Rozporządzenie Ministra Rolnictwa i Rozwoju Wsi w sprawie szczegółowych wymagań w zakresie jakości handlowej ziemniaków. 2003. (Dz. U. nr 194 poz. 1900 z 2003 roku).

Sawicka B., Pszczółkowski P. 2004. Fenotypowa zmienność struktury plonu odmian ziemniaka w warunkach środkowo-wschodniej Polski. [Phenotypic variation of yield structure of potato cultivars under conditions of mideastern Poland]. Biuletyn Instytutu Hodowli i Aklimatyzacji Roślin 232: 53-66.

Schenck M., Müller T. 2009. Impact of effective microorganisms and other biofertilizers on soil microbial characteristics, organic-matter decomposition and plant growth. Journal of Plant Nutrition and Soil Science 172 (5): 704-712. DOI: 10.1002/jpln.200800021.

Szewczuk Cz., Sugier D., Baran S., Bielińska E.J., Gruszczyk M. 2016. Wpływ preparatów użyźniających i zróżnicowanych dawek nawozów na wybrane właściwości chemiczne gleb oraz plon i cechy jakościowe bulw ziemniaka. [The impact of fertilising agents and different doses of fertilizers on selected soil chemical properties as well as the yield and quality traits of potato tubers]. Annales Universitatis Mariae Curie-Skłodowska, Sectio E, Agricultura LXXI (2): 65-79.

Trawczyński C., Bogdanowicz P. 2007. Wykorzystanie użyźniacza glebowego w aspekcie ekologicznej uprawy ziemniaka. [Utilization of soil fertilizer in ecological aspect of potato cultivation]. Journal of Research and Applications in Agricultural Engineering 52 (4): 94-97.

Turska E., Wielogórska G., Rymuza K. 2009. Oddziaływanie wybranych czynników agrotechnicznych na jakość bulw ziemniaka. [The influence of some agricultural factors on the quality of potato tubers]. Fragmenta Agronomica 26 (3): 156-161.

Zarzecka K., Gugała M. 2013. Wpływ użyźniacza glebowego UGmax na plon ziemniaka i jego strukturę. [The effects of soil fertilizer UGmax on yield of potato tubers and its structure]. Biuletyn Instytutu Hodowli i Aklimatyzacji Roślin 267: 105-110.

Zarzecka K., Gugała M., Mystkowska I., Baranowska A., Sikorska A. 2017. Jakość sensoryczna bulw ziemniaka w zależności od aplikacji UGmax. [Sensory quality of potato tubers depending on UGmax application]. Fragmenta Agronomica 34 (1): 117-125. 